\title{
Edge Detection Based on Fuzzy Logic and Expert System
}

\author{
Shuliang Sun ${ }^{1}$, Chenglian Liu ${ }^{1,2}$, Sisheng Chen ${ }^{1}$ \\ ${ }^{1}$ Department of Mathematics and Computer Science, \\ Fuqing Branch of Fujian Normal University, Fuqing \\ 2Department of Mathematics, Royal Holloway, \\ University of London, Egham, Surrey, TW20 \\ ${ }^{1}$ China \\ ${ }^{2} U K$
}

\section{Introduction}

The process of detecting outlines of an object and boundaries between objects and the background in the image is known as edge detection. It is an important tool used in many applications: such as image processing, computer vision and pattern recognition [1].

Linear time-invariant (LTI) filter is the most common method to the edge detection. On the condition of first-order filter, an edge is considered as an abrupt variation in gray level between two neighbor pixels. Then the aim is to find out the points in the image which the first-order derivative of the gray level is of high magnitude. The root mean square value (RMS) is often used as the threshold value to the input image [2].

Second order operators are used sometimes. LoG (Laplacian-of-Gaussian) [3] filter is the most commonly used. There are three drawbacks with this operator. Firstly, it produces the greater computational complexity. Secondly, it generates a continuous line to represent all edges in the input image, and is also not adequate to describe more general structures.

Fuzzy logic represents a powerful approach to decision making. Since the concept of fuzzy logic was formulated in 1965 by Zadeh, many researches have been carried out its applications in the various areas of digital image processing: such as image assessment, edge detection, image segmentation, etc [4]. Bezdek et al, trained a neural net to give the same fuzzy output as a normalized Sobel operator [5]. The advantage of the new method over the traditional edge detector is very apparent. In the system described in [6, 7], all inputs to the fuzzy inference systems (FIS) system are obtained by applying to the original image a high-pass filter, a first-order edge detector filter (Sobel operator) and a low-pass (mean) filter. The adopted fuzzy rules and the fuzzy membership functions are specified according to the kind of filtering to be executed.

\section{General description composition of the fuzzy inference system}

Fuzzy image processing is not a unique theory. It is a collection of different fuzzy approaches to image processing. Generally speaking, edge detection with fuzzy logic is 
composed of expert knowledge, fuzzification, membership modification, fuzzy set theory and defuzzification [8]. As shown in figure 1.

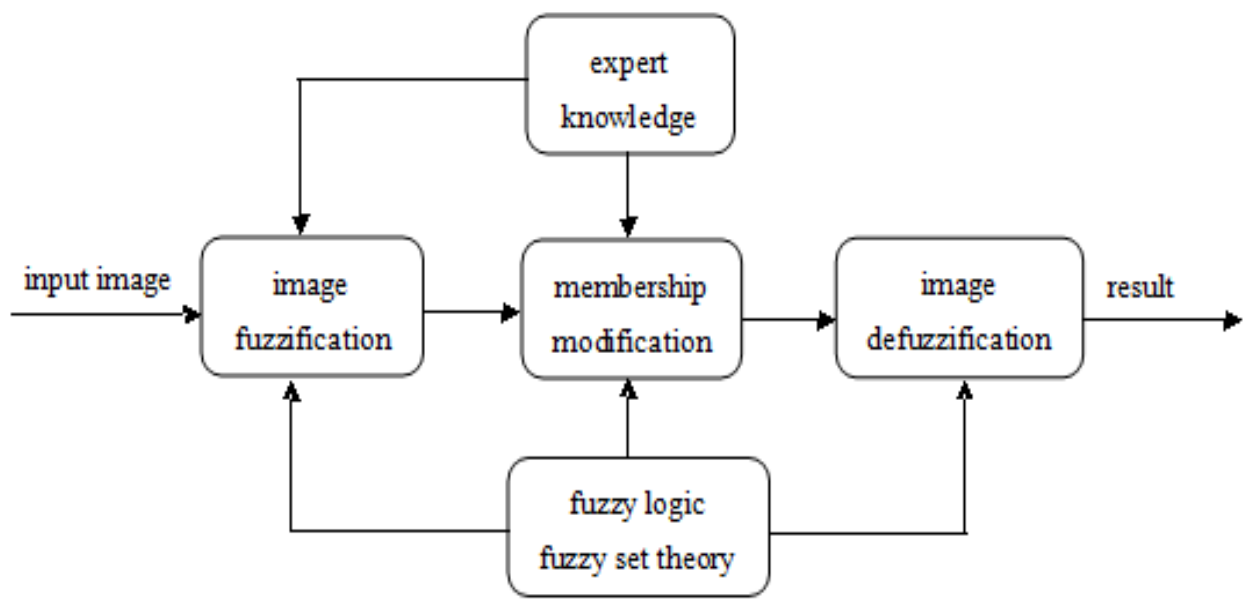

Fig. 1. The general structure of fuzzy image processing

The coding of image data (fuzzification) and decoding of the results (defuzzification) are steps that make possible to process images with fuzzy techniques. The main power of fuzzy image processing is in the middle step (modification of membership values). After the image datas are transformed from gray-level plane to the membership plane (fuzzification), appropriate fuzzy techniques modify the membership values. This can be a fuzzy clustering, a fuzzy rule-based approach, a fuzzy integration approach and so on.

Fuzzy image processing plays an important role in representing uncertain datas. There are many benefits of fuzzy image processing. Firstly, fuzzy techniques are able to manage the vagueness and ambiguity efficiently and deal with imprecise data. Secondly, fuzzy logic is easy to understand. Fuzzy reasoning is very simple in mathematical concepts.

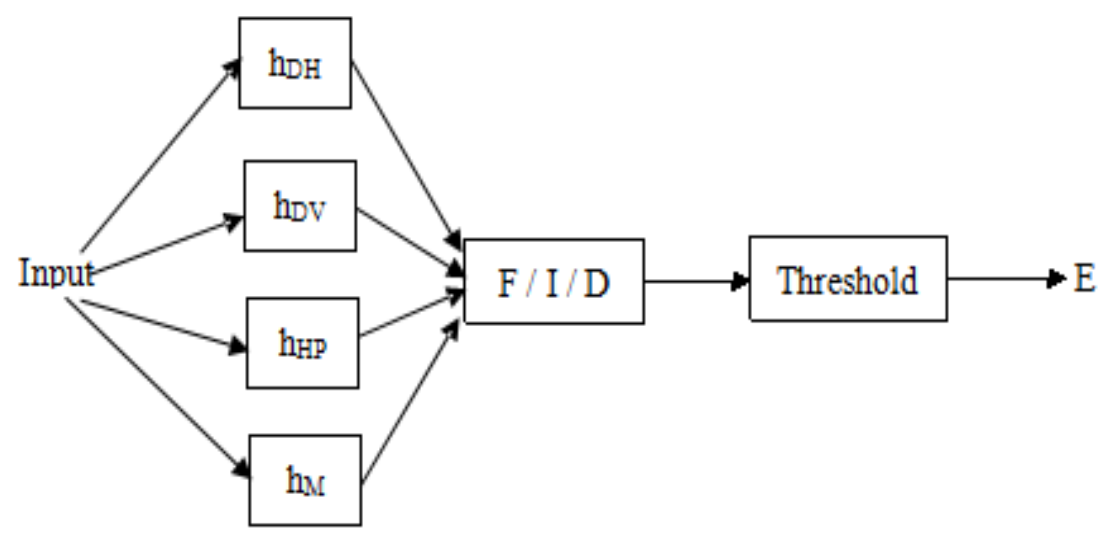

Fig. 2. Fuzzy inference system (FIS) applied to edge (E) detection 
In many image processing applications, expert knowledge is often used to work out the problems. Expert knowledge, in the form of fuzzy if-then rules, is used to deal with imprecise data in fuzzy set theory and fuzzy logic. Fuzzy method will be more suitable to manage the imperfection than the traditional way.

Input of the the fuzzy inference system (FIS) is the original image and composed by a highpass filter, a first-order edge detector filter (Sobel operator) and a low-pass (median) filter. It depicts in Figure 2.

In FIS , $h_{D H}$ and $h_{D V}$ are the Sobel operators used to estimate the first derivative of Image in horizontal and vertical directions. $h_{H P}$ and $h_{M}$ are the kernels of a high-pass and a low-pass (median) filters. F, I and D are the fuzzification, inference and defuzzification stages[9].

\section{Edge detection with FIS system}

\subsection{Image pretreatment}

Three linear and one non-linear (median) filters are used in this paper. A high-pass filter $\left(h_{H P}\right)$ and a median filter $\left(h_{M F}\right)$ are $3 \times 3$ masks.

\begin{tabular}{|c|c|c|}
\hline$[i-1, j-1]$ & {$[i-1, j]$} & {$[i-1, j+1]$} \\
\hline$[i, j-1]$ & {$[i, j]$} & {$[i, j+1]$} \\
\hline$[i+1, j-1]$ & {$[i+1, j]$} & {$[i+1, j+1]$} \\
\hline
\end{tabular}

Fig. 3.3 * 3 matrix mask

Sobel operators ( $h_{D H}$ and $h_{D V}$ ) are kernels with $3 \times 3$ elements given by [10]: $h_{D H}$ and $h_{D V}$ are Sobel operators used to estimate the first derivative of Image in horizontal and vertical directions.

$$
h_{D H}=\left[\begin{array}{ccc}
-1 & 0 & 1 \\
-2 & 0 & 2 \\
-1 & 0 & 1
\end{array}\right], \quad h_{D V}=\left[\begin{array}{ccc}
-1 & -2 & -1 \\
0 & 0 & 0 \\
1 & 2 & 1
\end{array}\right]
$$

Then the filtered images will be calculated through a bidimensional convolution operation, I is the original image:

$$
\begin{aligned}
& \mathrm{DH}=\mathrm{h}_{\mathrm{DH}} * \mathrm{I} \\
& \mathrm{DV}=\mathrm{h}_{\mathrm{DV}}{ }^{*} \mathrm{I}
\end{aligned}
$$

However, the result of convolution of the two Sobel kernels is combined by computing norm-2.

$$
D_{H V}=\sqrt{D H^{2}+D V^{2}}
$$

A high-pass filter $\left(\mathrm{h}_{\mathrm{HP}}\right)$ and a median filter $\left(\mathrm{h}_{\mathrm{MF}}\right)$ are defined as:

$$
h_{H P}=\left[\begin{array}{ccc}
-1 & -2 & -1 \\
-2 & 12 & -2 \\
-1 & -2 & -1
\end{array}\right]
$$




$$
\mathrm{h}_{\mathrm{MF}}=\operatorname{median}\left\{\mathrm{x}_{1}, \mathrm{x}_{2}, \mathrm{x}_{3}, \mathrm{x}_{4}, \mathrm{x}_{5}, \mathrm{x}_{6}, \mathrm{x}_{7}, \mathrm{x}_{8}, \mathrm{x}_{9}\right\}
$$

$x_{i}(i=1,2, \ldots, 9)$ is the element of $3 \times 3$ mask.

Then the filtered images will be calculated through a bidimensional convolution operation:

$$
\begin{aligned}
& \mathrm{HP}=\mathrm{h}_{\mathrm{HP}}{ }^{*} \mathrm{I} \\
& \mathrm{M}=\mathrm{h}_{\mathrm{MF}} \text { *I }
\end{aligned}
$$

Laplacian operator and Gaussian function are separately defined as:

$$
\begin{gathered}
\nabla^{2} f=\frac{\partial^{2} f}{\partial x^{2}}+\frac{\partial^{2} f}{\partial y^{2}} \\
h(x, y)=\exp \left(-\frac{x^{2}+y^{2}}{2 \sigma^{2}}\right)
\end{gathered}
$$

Then LoG operator is formed by the convolution between Gaussian function and Laplacian operator.

$$
\nabla^{2} h=\left(\frac{r^{2}-\sigma^{2}}{\sigma^{4}}\right) \exp \left(-\frac{r^{2}}{2 \sigma^{2}}\right)
$$

Here suppose $r^{2}=x^{2}+y^{2}$.

\subsection{Fuzzy sets and fuzzy membership functions}

Three fuzzy sets are made up to represent each variable's intensities; these sets are symbolized to the linguistic variables "low", "medium" and "high".

The adopted membership functions for the fuzzy sets are Gaussian function and sigmoid function. For the linguistic variables "low" and "high", sigmoid function is chosen; Gaussian function is used for the variable "medium" with the mean 127.5. As shown in Figure 4.

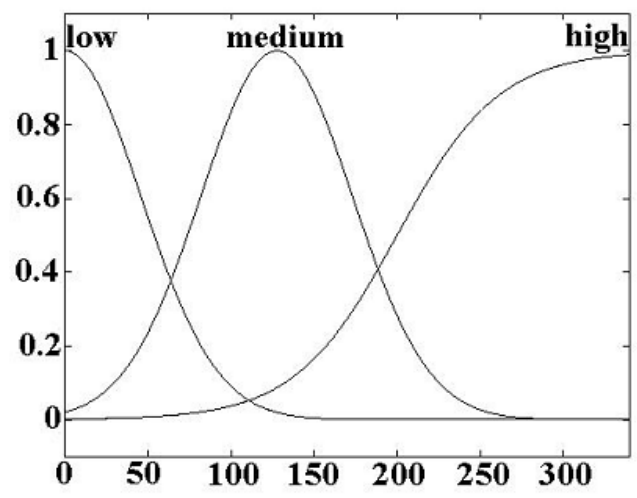

Fig. 4. Membership functions of the fuzzy sets 
By the defined fuzzy rules, the output of this fuzzy system is classified to one of three classes [11,12]. Output membership functions are shown in figure 5.

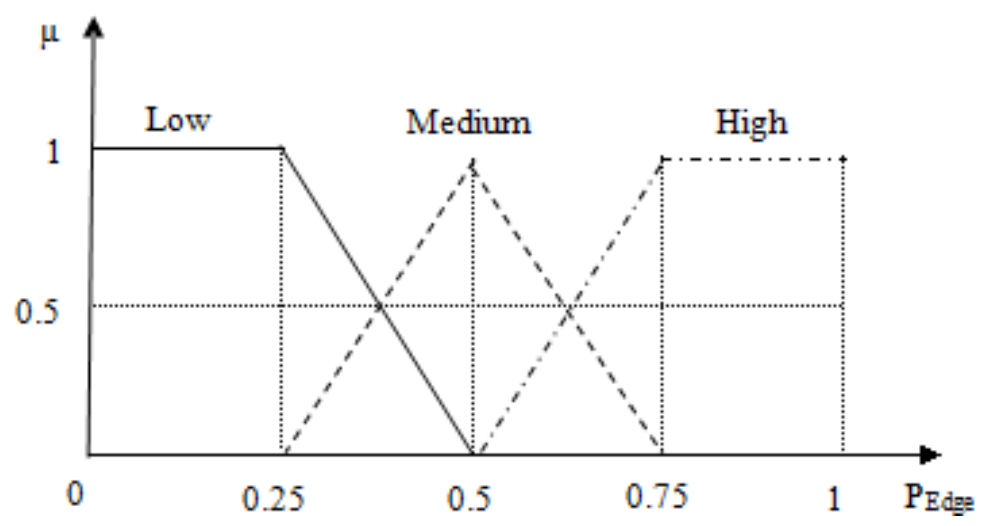

Fig. 5. Output membership functions

Fuzzy inference rules are applied to assign the three fuzzy sets characterized by membership functions $\mu_{\text {High }}, \mu_{\text {Medium }}$, and $\mu_{\text {Low }}$ to the output set.

\subsection{Fuzzy inference rules}

The fuzzy inference rules are defined in such a way, and the rules are shown below:

1. IF (M is low) and ( $h_{D V}$ is low) and (HP is low) THEN ("Edge" is low).

2. IF ( $M$ is low) and ( $h_{\text {DV }}$ is low) and (HP is medium) THEN ("Edge" is low).

3. IF ( $\mathrm{M}$ is low) and ( $\mathrm{h}_{\mathrm{DV}}$ is low) and (HP is high) THEN ("Edge" is low).

4. IF ( $\mathrm{M}$ is low) and ( $\mathrm{h}_{\mathrm{DV}}$ is medium) and (HP is low) THEN ("Edge" is low).

5. IF ( $\mathrm{M}$ is low) and ( $\mathrm{h}_{\mathrm{DV}}$ is medium) and (HP is medium) THEN ("Edge" is low).

6. IF ( $\mathrm{M}$ is low) and ( $\mathrm{h}_{\mathrm{DV}}$ is medium) and (HP is high) THEN ("Edge" is medium).

7. IF ( $\mathrm{M}$ is low) and ( $\mathrm{h}_{\mathrm{DV}}$ is high) and (HP is low) THEN ("Edge" is low).

8. IF ( $\mathrm{M}$ is low) and ( $\mathrm{h}_{\mathrm{DV}}$ is high) and (HP is medium) THEN ("Edge" is high).

9. IF ( $M$ is low) and ( $\mathrm{h}_{\mathrm{DV}}$ is high) and (HP is high) THEN ("Edge" is high).

10. IF ( $\mathrm{M}$ is medium) and ( $\mathrm{h}_{\mathrm{DV}}$ is low) and (HP is low) THEN ("Edge" is low).

11. IF ( $M$ is medium) and ( $h_{D V}$ is low) and (HP is medium) THEN ("Edge" is low).

12. IF ( $\mathrm{M}$ is medium) and ( $\mathrm{h}_{\mathrm{DV}}$ is low) and (HP is high) THEN ("Edge" is medium).

13. IF ( $\mathrm{M}$ is medium) and ( $\mathrm{h}_{\mathrm{DV}}$ is medium) and (HP is low) THEN ("Edge" is medium).

14. IF ( $\mathrm{M}$ is medium) and ( $\mathrm{h}_{\mathrm{DV}}$ is medium) and (HP is medium) THEN ("Edge" is medium).

15. IF ( $\mathrm{M}$ is medium) and ( $\mathrm{h}_{\mathrm{DV}}$ is medium) and (HP is high) THEN ("Edge" is high).

16. IF ( $\mathrm{M}$ is medium) and ( $\mathrm{h}_{\mathrm{DV}}$ is high) and (HP is low) THEN ("Edge" is medium).

17. IF ( $M$ is medium) and ( $\mathrm{h}_{\mathrm{DV}}$ is high) and (HP is medium) THEN ("Edge" is high).

18. IF ( $\mathrm{M}$ is medium) and ( $\mathrm{h}_{\mathrm{DV}}$ is high) and (HP is high) THEN ("Edge" is high).

19. IF ( $M$ is high) and ( $h_{D V}$ is low) and (HP is low) THEN ("Edge" is low).

20. IF ( $M$ is high) and ( $h_{D V}$ is low) and (HP is medium) THEN ("Edge" is medium).

21. IF ( $\mathrm{M}$ is high) and ( $\mathrm{h}_{\mathrm{DV}}$ is low) and (HP is high) THEN ("Edge" is medium). 
22. IF ( $\mathrm{M}$ is high) and ( $\mathrm{h}_{\mathrm{DV}}$ is medium) and (HP is low) THEN ("Edge" is medium).

23. IF ( $\mathrm{M}$ is high) and ( $\mathrm{h}_{\mathrm{DV}}$ is medium) and (HP is medium) THEN ("Edge" is medium).

24. IF ( $\mathrm{M}$ is high) and ( $\mathrm{h}_{\mathrm{DV}}$ is medium) and (HP is high) THEN ("Edge" is high).

25. IF ( $\mathrm{M}$ is high) and ( $\mathrm{h}_{\mathrm{DV}}$ is high) and (HP is low) THEN ("Edge" is medium).

26. IF ( $\mathrm{M}$ is high) and ( $\mathrm{h}_{\mathrm{DV}}$ is high) and (HP is medium) THEN ("Edge" is high).

27. IF ( $\mathrm{M}$ is high) and ( $\mathrm{h}_{\mathrm{DV}}$ is high) and (HP is high) THEN ("Edge" is high).
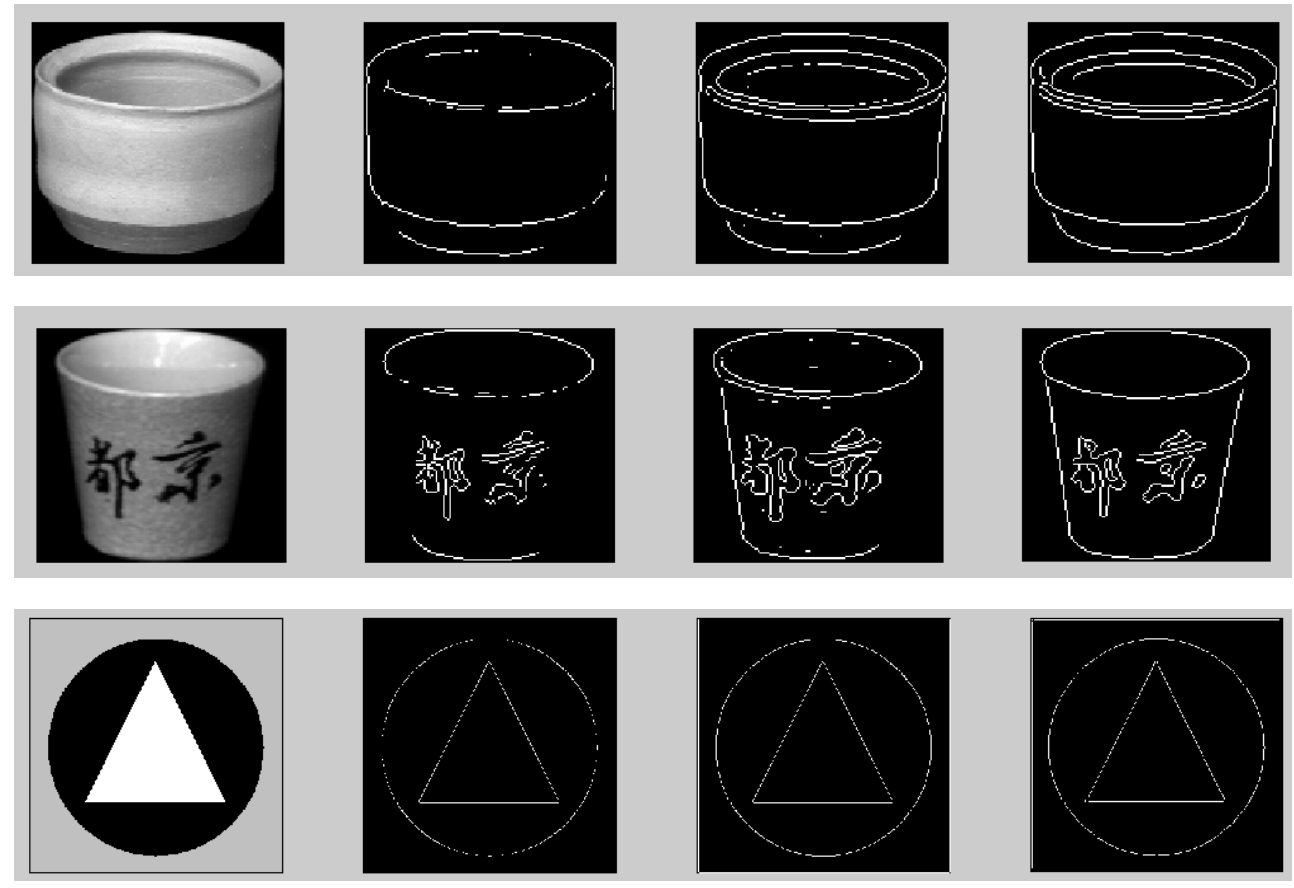

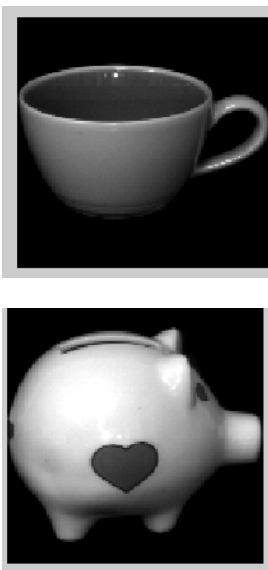

(a)
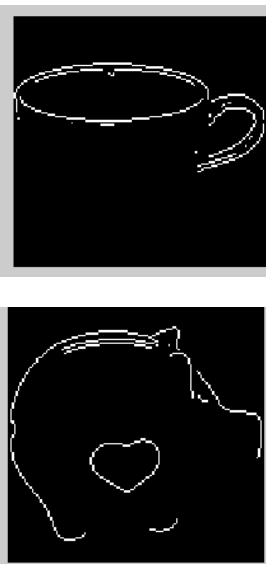

(b)
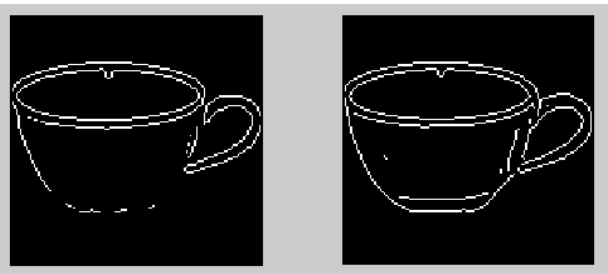

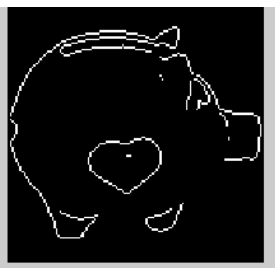

(c)

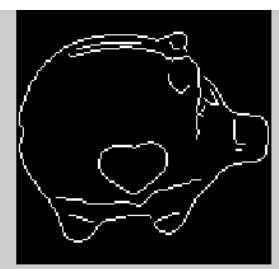

(d)

Fig. 6. Using different methods to detect the image with gradation of gray levels 


\subsection{Fuzzy logical operations and defuzzification}

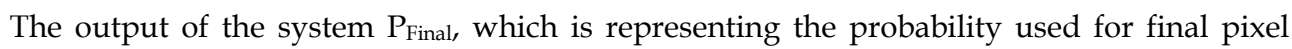
classification as edge or not, is reckoned on a singleton fuzzifier. Mamdani defuzzifier method [13] is given by:

$$
P_{\text {Final }}=\frac{\sum_{l=1}^{M} y^{-l}\left(\prod_{i=1}^{n} \mu_{k_{i}^{l}}\left(\alpha_{i}\right)\right)}{\sum_{l=1}^{M}\left(\prod_{i=1}^{n} \mu_{k_{i}^{l}}\left(\alpha_{i}\right)\right)}
$$

where $a_{i}$ are the fuzzy sets associated with the fuzzy rule base, $\bar{y}$ is the output class center and $\mathrm{M}$ is the number of fuzzy rules being considered.

\section{Experiments}

The proposed fuzzy edge detection method is simulated using MATLAB 7.0 on different images, and its performance is compared to that of the Sobel and LoG operator. In Figure 6, (a) is the original image, (b) is the image that the Sobel operator with threshold automatically estimated from image's RMS value. (c) is the image with LoG operator to detect edges, and the threshold is computed automatically. The FIS system, as shown (d), not only detects edges much better, but also makes the output image without noise.

Form above the experiments, it can be obviously shown that no matter how different images are tested, such as from bright to dim or from natural to artificial, the FIS system proposed in this paper is much better than Sobel and LoG operator in edge detection. The only disadvantage is that FIS system is not as simple as Sobel and LoG operator.

\section{Conclusion}

In this paper, FIS has been presented. The three edge strength values used as fuzzy system inputs were fuzzified using Gaussian membership functions and sigmoid function. Fuzzy ifthen rules are used to modify the membership to one of low, medium, and high classes. Finally, Mamdani defuzzifier method is used to form the final edge image. By the simulation results, it can be concluded that though more computationally expensive than Sobel and LoG operators, the FIS system is superior in greater robustness to detect edge, and also advantage in edge detection exactly and noise removed clearly.

\section{References}

[1] J. C. Bezdek. (1981). Pattern Recognition with Fuzzy Objective Functions. Plenum, New York.

[2] M. N. Mahani, M. K. Moqadam, H. N. pour, etc. (2008). Dynamic Edge Detector Using Fuzzy Logic, CSISS 2008, Sharif University ofTechnology, Kish.

[3] L. Liang and C. Looney. (2003). Competitive Fuzzy Edge Detection, Applied Soft Computing , pp. $123-137$.

[4] G. Mansoori and H. Eghbali. (2006). Heuristic edge detection using fuzzy rule-based classifier, Journal of Intelligent and Fuzzy Systems, Volume 17, Number 5, pp. 457469. 
[5] Kuo, R. J. (1997). A robotic die polishing system through fuzzy neural networks, Computer Industry, Volume 32, Number 3, pp. 273-280.

[6] Tizhoosh H.R.(2002). Fast fuzzy edge detection, Proceedings of Fuzzy Information Processing Society, pp. 239-242.

[7] Lin, C. T., Lee, S. G.(1994). Reinforcement structure/parameter learning for neural network based fuzzy logic systems, IEEE Trans. Fuzzy Systems, Volume 2, Number 1 , pp. 46-63.

[8] Shahana B., Prasad B., E D Nagendra Prasad T. (2011). A New Approach for Edge Detection Using First Order Techniques. IJCSt , Volume 2, Number 1, pp. 78-82.

[9] Abdallah A. Alshennawy, and Ayman A. Aly. (2009). Edge Detection in Digital Images Using Fuzzy Logic Technique. World Academy of Science, Engineering and Technology 51, pp. 178-186.

[10] Cristiano Jacques Miosso1, Adolfo Bauchspiess. (2001). Fuzzy Inference System Applied to Edge Detection in Digital Images. Proceedings of the $V$ Brazilian Conference on Neural Networks - V Congresso Brasileiro de Redes Neurais. April 2-5, - PUC, Rio de Janeiro - RJ - Brazil, pp. 481-486.

[11] Yujing Zhang. (2008). Image Treatment and Analysis Technology. Beijing, pp. 189-193.

[12] Wafa B., Fardin A. T., Om-Kolsoom S. (2009). Fuzzy Edge Detection Based on Pixel's Gradient and Standard Deviation Values. PROCEEDINGS OF THE IMCSIT. Volume 4, pp. 7-10.

[13] Aborisade, D. O. (2010). Fuzzy Logic Based Digital Image Edge Detection. Global Journal of Computer Science and Technology, Volume 10, Number 14, pp. 78-83. 


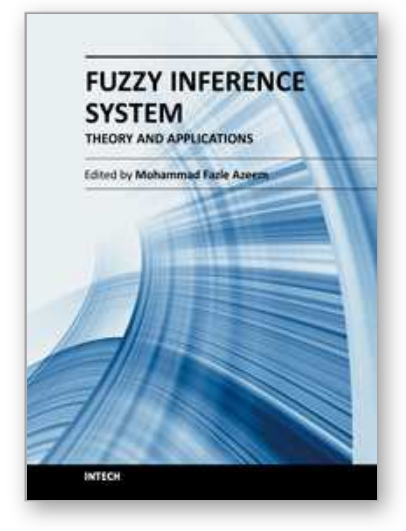

\author{
Fuzzy Inference System - Theory and Applications \\ Edited by Dr. Mohammad Fazle Azeem
}

ISBN 978-953-51-0525-1

Hard cover, 504 pages

Publisher InTech

Published online 09, May, 2012

Published in print edition May, 2012

This book is an attempt to accumulate the researches on diverse inter disciplinary field of engineering and management using Fuzzy Inference System (FIS). The book is organized in seven sections with twenty two chapters, covering a wide range of applications. Section I, caters theoretical aspects of FIS in chapter one. Section II, dealing with FIS applications to management related problems and consisting three chapters. Section III, accumulates six chapters to commemorate FIS application to mechanical and industrial engineering problems. Section IV, elaborates FIS application to image processing and cognition problems encompassing four chapters. Section V, describes FIS application to various power system engineering problem in three chapters. Section VI highlights the FIS application to system modeling and control problems and constitutes three chapters. Section VII accommodates two chapters and presents FIS application to civil engineering problem.

\title{
How to reference
}

In order to correctly reference this scholarly work, feel free to copy and paste the following:

Shuliang Sun, Chenglian Liu, Sisheng Chen (2012). Edge Detection Based on Fuzzy Logic and Expert System, Fuzzy Inference System - Theory and Applications, Dr. Mohammad Fazle Azeem (Ed.), ISBN: 978-953-510525-1, InTech, Available from: http://www.intechopen.com/books/fuzzy-inference-system-theory-andapplications/edge-detection-based-on-fuzzy-logic-and-expert-system

\section{INTECH}

open science | open minds

\author{
InTech Europe \\ University Campus STeP Ri \\ Slavka Krautzeka 83/A \\ 51000 Rijeka, Croatia \\ Phone: +385 (51) 770447 \\ Fax: +385 (51) 686166 \\ www.intechopen.com
}

\author{
InTech China \\ Unit 405, Office Block, Hotel Equatorial Shanghai \\ No.65, Yan An Road (West), Shanghai, 200040, China \\ 中国上海市延安西路65号上海国际贵都大饭店办公楼 405 单元 \\ Phone: +86-21-62489820 \\ Fax: +86-21-62489821
}


(C) 2012 The Author(s). Licensee IntechOpen. This is an open access article distributed under the terms of the Creative Commons Attribution 3.0 License, which permits unrestricted use, distribution, and reproduction in any medium, provided the original work is properly cited. 